\title{
LIBERALISMO ECONÓMICO Y DOCTRINA MORAL CATÓLICA
}

\author{
RODRIGO HIDALGO TORRES*, O.P.
}

Resumen: En el presente trabajo se efectúa un repaso a la Doctrina Social de la Iglesia Católica (DSI) analizándose su posible compatibilidad con el liberalismo económico y proponiendo a la Escuela Austriaca de economía (con su énfasis en la creatividad y la función empresarial) como punto de encuentro más prometedor entre la moral católica y el mercado libre.

Palabras clave: Doctrina Social de la Iglesia, mercado, liberalismo, función empresarial, Escuela Austriaca.

Clasificación JEL: A10, D40, E24, 130, O10.

Abstract: This article presents an analysis of the current tenets of the Social teachings of the Catholic Church and their possible compatibility with the free market theory and practice. According to the Author, the teachings of the Austrian School of Economics, around creative entrepreneurship and dynamic efficiency, can provide a new and fruitful nexus between the Catholic Church and the free market.

Key words: Catholic Social Doctrine, market, classical liberalism, entrepreneurship, Austrian School.

JEL Classification: A10, D40, E24, 130, 010.

* Doctorando del programa de doctorado en Economía de la Escuela Austriaca de la Universidad Rey Juan Carlos de Madrid.

Procesos de Mercado: Revista Europea de Economía Política Vol. VIII, n.. 1 , Primavera 2011, pp. 121 a 160 


\section{I \\ EL LIBERALISMO ECONÓMICO Y LA DOCTRINA CATÓLICA}

La Escuela Austriaca se encuadra dentro de las grandes ramas del liberalismo contemporáneo - y desde esa conexión vamos a estudiarla-, por ello, primero, revisaremos cuál ha sido la postura más reciente de la Iglesia respecto a esta doctrina.

\section{Un conflicto histórico: la iglesia y el liberalismo}

El capitalismo como realidad económica no es separable del substrato ideológico que lo sustenta: el liberalismo político. Por eso, antes de ver las relaciones entre liberalismo económico y moral católica, debemos ver las relaciones más generales entre liberalismo y catolicismo.

Debemos empezar diciendo que las relaciones entre la Iglesia y las doctrinas filosóficas y económicas del liberalismo han sufrido a lo largo del tiempo una progresiva transformación, traducida en un mayor acercamiento de sus respectivas posiciones, las que en un principio se vieron como completamente enfrentadas y sin posibilidad de diálogo. ${ }^{1}$ La razón estaría en las profundas transformaciones ideológicas que al interior de ambas doctrinas se habrían producido. Frases que distinguen entre el «capitalismo salvaje» y la situación actual de las «sociedades modernas», expresan la perspectiva histórica que el magisterio asume, pues se es consciente que el conflicto social no se puede ya plantear en la misma forma como lo hiciera, por ejemplo, León XIII.

Tampoco debemos olvidar que el conflicto liberalismo-catolicismo ha estado enmarcado en un conflicto histórico mucho más

1 Puede consultarse E.M. Ureña., «Liberalismo: su evolución y transformación ideológica» en Corintios XIII, n. 58, 1991; R. Rincón O., «Los sistemas económicos» en Manual de Doctrina Social de la Iglesia, BAC, Madrid 1993, cap. 25; D. Villey., «La economía de mercado ante el pensamiento católico» en Cuadernos del pensamiento Liberal, n. ${ }^{\circ}$, Marzo de 1987. 
amplio, que podemos hacerlo retroceder hasta el Renacimiento, entre Iglesia y modernidad, pues en definitiva ha sido el liberalismo, como síntesis de una serie de corrientes filosóficas y culturales, la gran fuerza ideológica que ha posibilitado la quiebra del ancien regime instaurando una nueva mentalidad que ha tenido repercusiones directas en la configuración de un estilo de organización política y económica diferentes al paradigma medieval. Dice el gran conocedor del liberalismo J. Gray, «A pesar de todos sus antecedentes en el mundo antiguo, la corriente liberal es una creación de la modernidad, por cuanto presupone los logros culturales - la moral de la individualidad y una diversidad de formas de vida en sociedad- mediante los cuales se llega a la caracterización más adecuada del mundo moderno.» ${ }^{2}$ Por tanto, la reconciliación liberalismo-catolicismo, pasa por la reconciliación con la modernidad en su conjunto como hecho cultural dominante.

\section{El magisterio y la sociedad liberal}

La Iglesia antes de reconciliarse con el capitalismo, o de aceptar sus grandes principios de desenvolvimiento, que desde mi punto de vista no queda suficientemente aclarado hasta la encíclica Centesimus Annus de Juan Pablo II, ella previamente ha ido aceptando unos presupuestos jurídicos-filosóficos que tienen carácter previo al hecho económico mismo y sin los cuales el capitalismo no puede funcionar. La primera reconciliación ha sido la aceptación de los grandes presupuestos de la democracia liberal: la soberanía popular, el Estado de derecho, la alternancia en el poder, el pluralismo cultural, la separación Iglesia-Estado, la defensa y promoción de las libertades, etc. Dice Novak, «aunque la Iglesia católica durante el siglo XIX y los inicios del siglo XX se opuso al liberalismo como ideología, ella lentamente ha venido a dar apoyo a la eficacia moral de las instituciones liberales. De una manera clara ha apoyado la institución de los derechos humanos.

\footnotetext{
2 J. Gray, Liberalismo, Madrid 1994, p. 138.
} 
Pero también, aunque más lentamente, ha venido a dar apoyo a las instituciones democráticas y al mercado orientado al desarrollo económico.» ${ }^{3}$

Ahora bien, si tuviéramos que señalar los grandes hitos de aceptación por parte del magisterio de esta nueva mentalidad, hija de la Ilustración, creo que habría que señalar la encíclica Pacem in Terris de Juan XXIII del año 1963 que tendría una continuidad directa con la encíclica Gaudium et Spes del Concilio Vaticano II. «Entrar en el mundo de Juan XXIII es, para una persona educada por las instituciones liberales, una tremenda satisfacción. Aquí uno puede encontrar un claro y explícito apoyo en la concepción de los derechos humanos (deberes) que encarnan las instituciones liberales.» 4

De su lectura se desprende un sí positivo -y quizás más rotundo que en otros documentos- a las instituciones jurídicopolítico-económicas del mundo liberal: respeto a la propiedad privada y a los derechos humanos y sociales; se insiste en los deberes del ciudadano, en la participación política; se llama a la necesidad de crear organismos internacionales que velen por la paz y la prosperidad mundial; se habla de ecumenismo entre cristianos y con otras religiones, como a su vez de la necesidad de impulsar el diálogo con los no creyentes; a todos, sin distinción alguna, se llama al compromiso en la defensa y promoción de los derechos humanos; se espera que el perfeccionamiento de la sociedad se haga por sucesivas reformas y no por revoluciones, etc.

\section{La visión pesimista de la economía liberal de Pablo VI}

A la imagen "optimista» del mundo moderno reflejada tanto en Juan XXIII como en la Gaudium et Spes, le seguirá la visión de Pablo VI mucho más «pesimista» o si se quiere más realista de los límites y desafíos que enfrenta el mundo moderno.

\footnotetext{
${ }^{3}$ M. Novak, Freedom with Justice. Catolic Social Thought and Liberal Institution, Harper and Row, Publisher, S. Francisco 1984, p. 2.

${ }^{4}$ M. Novak., p. 126.
} 
A continuación quiero citar dos textos de este Papa, que por la claridad y contundencia con que expresa su pensamiento los propongo como modelos donde poder encontrar todos aquellos rasgos que el magisterio ve como incompatibles entre mundo moderno y fe cristiana.

A raíz de un hecho tan importante en la configuración del mundo moderno como es la industrialización, dice el Papa en Populorum progressio, n. $\mathrm{o} 26$.

Pero, por desgracia, sobre estas nuevas condiciones de la sociedad ha sido construido un sistema que considera el lucro como motor esencial del progreso económico; la concurrencia, como ley suprema de la economía; la propiedad privada de los medios de producción, como un derecho absoluto, sin límites ni obligaciones sociales correspondientes. Este liberalismo sin freno que conduce a la dictadura, justamente fue denunciado por Pío XI como generador del imperialismo del dinero.

Años más tarde, en Octogesima adveniens, n. ㅇ 26, haciendo una contraposición a la filosofía marxista el Papa exhorta a los cristianos, y dice:

Tampoco apoya el cristiano la ideología liberal, que cree exaltar la libertad individual sustrayéndola de toda limitación, estimulándola con la búsqueda exclusiva del interés y del poder, y considerando las solidaridades sociales como consecuencias más o menos automáticas de iniciativas individuales y no ya como un fin o motivo primario del valor de la organización social.

Creer que en el pensamiento de Pablo VI anidan deseos de «restauración» sería traicionar el pensamiento de un pontífice profundamente comprometido con la causa de la justicia y de la inculturación de la fe en el mundo contemporáneo. En la misma carta apostólica un poco más adelante dirá: «Ciertamente hay que mantener la iniciativa individual» $(\mathrm{OA}, 35)$, que como hemos visto es un rasgo característico de la ideología liberal. Pero su percepción de esta ideología no deja de ser pesimista pues ella descansaría sobre unos presupuestos antropológicos falsos, los que 
tarde o temprano tiende a absolutizar sus principios: «motor esencial», «ley suprema» o «búsqueda exclusiva», degradando la condición humana, por eso advierte a los cristianos que no deben olvidar «que en su raíz misma el liberalismo filosófico es una afirmación errónea de la autonomía del individuo en su actividad, sus motivaciones, el ejercicio de su libertad.» (OA, 35).

Pablo VI sabe que la «sociedad capitalista» ha generado un sinfín de bienes y servicios como nunca antes visto, pero esa realidad está coexistiendo con otras marcadas por flagrantes injusticias: bolsas de pobreza en el interior de las sociedades desarrolladas y con diferencias abismales a nivel internacional entre países ricos y pobres. ¿Cuál es la solución? pues la respuesta quiere ser ni marxismo ni liberalismo económico, ¿quizás una «vía media», con posibilidad a la iniciativa individual, enmarcada dentro de un contexto de justicia social posibilitada por la función asistencial del Estado? ¿al estilo de la sociedad del bienestar? ¿o al estilo de la economía social de mercado alemana? pues puede ser.

En todo caso la respuesta definitiva vendrá con Juan Pablo II en Centesimus Annus donde las críticas ya no son tanto al capitalismo, única alternativa posible en ese momento - aunque su aceptación se hace con una serie de condiciones morales previas que garanticen su justo funcionamiento- como a «un sistema ético-cultural» (C.A., 39), que tiende a olvidar que la economía es para el hombre y no el hombre para la economía.

Si desde Centesimus Annus el problema actual de la relación economía-cristianismo hay que plantearlo a nivel ético-cultural y no tanto en la superioridad de la economía de mercado para producir y distribuir bienes y servicios, hecho puesto de manifiesto frente a cualquier otra alternativa histórica, la pregunta es ¿Cuáles son las causas que han hecho que el sistema cultural donde la economía se desenvuelve esté tan profundamente debilitado, con las consecuencias que los pontífices repetidamente señalan, y sea incapaz de generar adhesiones?

Adelantemos que la crisis que padece la civilización también la comparte el liberalismo contemporáneo. En el punto dos veremos qué respuesta dará el liberalismo. Lo estudiaremos, primero, desde la vertiente austriaca y luego desde la respuesta neoconservadora, ambas profundamente emparentadas. 
Revisemos ahora cuáles han sido las principales objeciones del magisterio reciente a la economía de mercado.

\section{Objeciones del magisterio a la economía de mercado}

Si los pontífices no han cesado de mostrar su preocupación por la crisis cultural que vive la modernidad y en todas sus intervenciones han señalado aquellos puntos que consideran incompatibles con la fe cristiana, algo similar ha ocurrido con el capitalismo, cuya aceptación como forma de organización económica - la menos mala de las posibles_ - ha sido mucho más lenta. Si el mundo moderno presenta límites insalvables, la economía de mercado, también. Las principales objeciones a la economía de mercado podrían ser las siguientes.

1. Supone la absolutización de la economía, cuando en realidad ésta es sólo un aspecto y una dimensión de la compleja actividad humana;

2. La libertad económica, que sólo es un elemento de la libertad humana, se declara autónoma, rompiendo el lazo umbilical con la verdad y la solidaridad;

3. Considera al hombre más como productor o consumidor de bienes que como sujeto que produce y consume para vivir;

4. Al olvidar la verdad objetiva y trascendente, corrompe la cultura y la vida moral de las naciones. ${ }^{5}$

Desarrollaremos ahora en tres puntos, que considero los más representativos, los «límites» y las posibles correcciones puestos por el magisterio al capitalismo, previa aceptación de sus postulados básicos de organización.

${ }^{5}$ R. Rincón Orduña, «Los sistemas económicos» en Manual de Doctrina Social de la Iglesia, BAC, Madrid 1993, p. 600. 
a) La mercantilización de la sociedad

Aceptando que el mercado «sea el instrumento más eficaz para colocar los recursos y responder más eficazmente a las necesidades» (C.A. 34) sin embargo este «instrumento» no es suficiente para cubrir una serie de necesidades que al no poseer el incentivo necesario para su transacción en el mercado nadie quiere invertir en ellas. En otras palabras, no podemos dejar todo al juego de mercado pues éste se mueve con eficacia solo donde descubre incentivos económicos, dejando a un lado una serie de realidades que carecen de tal propiedad; aún más, existen realidades humanas que escapan por su misma naturaleza a la lógica de la oferta y la demanda. «Hay bienes que, por su naturaleza, no se pueden ni se deben vender o comprar» (C.A. 40b). Por eso no se puede caer en una «idolatría del mercado» (C.A. 40b).

La respuesta del magisterio a este respecto se mueve en una clara perspectiva humanista, la cual quiere mostrarnos la centralidad del ser humano frente a los mecanismos impersonales de mercado, puesto que "por encima de la lógica de los intercambios a base de los parámetros y de sus formas justas, existe algo que es debido al hombre porque es hombre, en virtud de su eminente dignidad.» (C.A. 34).

¿Cómo solventar aquellas situaciones donde la iniciativa privada no llega? la respuesta se mueve en el ámbito de la doctrina de la subsidiaridad donde «una estructura de orden superior no debe interferir en la vida interna de un grupo social de orden inferior, privándola de sus competencias.» (C.A. 48d). En este sentido «es deber del Estado proveer la defensa y tutela de los bienes colectivos como son el ambiente natural y el ambiente humano, cuya salvaguarda no puede estar asegurada por los simples mecanismos de mercado.» (C.A. 40).

\section{b) Los ajustes automáticos del mercado}

Otro tema relacionado con el anterior: «la idolatría del mercado», es también la excesiva confianza que pone el liberalismo en los ajustes automáticos que el mercado puede hacer desde la sola 
espontaneidad de las fuerzas que allí intervienen. De la misma manera que el magisterio ha dicho que no todo puede entrar en la dinámica de la oferta y la demanda, también se ha pronunciado que no todo puede quedar a expensas de las leyes de la competencia, como si éstas desde su misma dinámica pudieran engendrar condiciones de justicia. A este respecto el magisterio de Pablo VI es claro:

La sola iniciativa individual y el simple juego de la competencia no serían suficientes para asegurar el éxito del desarrollo..Toca a los poderes públicos escoger y ver el modo de imponer los objetivos que hay que proponerse, las metas que hay que fijar, los medios para llegar a ellas, estimulando al mismo tiempo todas las fuerzas agrupadas en esta acción común. (P.P. 33).

La razón que nos da el pontífice del por qué la necesidad de una «sana» planificación son las mismas que hemos podido ver antes, es decir, una razón antropológica. Dejar actuar a la competencia sin ningún tipo de trabas puede traducirse en mayores sufrimientos para los más desprotegidos: «todo programa concebido para aumentar la producción, al fin y al cabo, no tiene otra razón de ser que el servicio de la persona. Si existe es para reducir las desigualdades, combatir las discriminaciones, librar al hombre de la esclavitud, hacerle capaz de ser por sí mismo agente responsable de su mejora material, de su progreso moral y de su desarrollo espiritual.» (P.P. 34).

Pablo VI era consciente de que una planificación radical de la sociedad se traduciría en una colectivización de los medios de producción, produciéndose la pérdida de la libertad, la cual «excluirá el ejercicio de los derechos fundamentales de la persona humana.» (P.P. 33). Por eso esta programación económica ha de hacerse con el «cuidado de asociar a esta empresa las iniciativas privadas y los cuerpos intermedios» (P.P. 33) a fin de encontrar un justo equilibrio entre lo privado y lo público. Pablo VI, según mi opinión, estaría en la línea de aceptación de un modelo de economía mixta con participación del Estado e iniciativa privada.

Juan Pablo II años más tarde, con un contexto social y económico distinto al de Pablo VI, sin negar lo anterior, se mostrará 
un poco más cauto a la hora de asociar la intervención del Estado en economía con la ayuda a los más desfavorecidos. Dice:

al intervenir directamente y quitar responsabilidad a la sociedad, el Estado asistencial provoca la pérdida de energías humanas y el aumento exagerado de los aparatos públicos, dominados por lógicas burocráticas más que por la preocupación de servir a los usuarios, con enorme crecimiento de los gastos. (C.A. 48e)

\section{c) La rivalidad y la impersonalidad en el ámbito del mercado}

Otro límite infranqueable que ha visto el magisterio en su reflexión en torno al mercado es, por un lado, la rivalidad o competencia que lleva el proceso mismo, y por otro, el anonimato que significa el estar trabajando en una red de intercambios comerciales que no sabes dónde empieza ni donde termina, sumado a una racionalidad utilitarista que genera el mercado de trabajo, medida aquélla en términos de beneficios personales que genera el asociarte a tal o cual empresa. Todo lo anterior se traduce en una pérdida de lazos comunitarios, indispensables en el proceso de sociabilidad del ser humano.

La respuesta del magisterio a esta tendencia «atomizante» del mercado se llama solidaridad, la cual vendría a expresar la relación de unidad de todos los seres humanos, los de cerca y los de lejos, donde el sufrimiento de unos compromete a los otros. Frente a una economía impersonal que sólo busca beneficios individuales, la respuesta es la solidaridad como la manera de superar los problemas de la sociedad actual. «La interdependencia debe convertirse en solidaridad, fundada en que los bienes de la creación están destinados a todos. Y lo que la industria humana produce con la elaboración de las materias primas y con la aportación del trabajo debe servir igualmente al bien de todos.» (S.R.S. 39). Además, frente a la tendencia histórica de preeminencia del capital sobre el trabajo, fuente de un sinfín de explotaciones, también se nos habla de ejercitar la solidaridad «allí donde lo requiere la degradación social del sujeto del trabajo, la explotación de los trabajadores y las crecientes zonas de miseria e incluso de hambre» (L.E. 8). 
Otro remedio que ha visto el magisterio a fin de frenar la tendencia hacia el anonimato es la potenciación de las instancias intermedias de la sociedad: todo tipo de asociaciones y por supuesto la labor de la familia como espacio de personalización. «Para superar la mentalidad individualista, hoy día tan difundida, se requiere un compromiso concreto de solidaridad y caridad, que comienza dentro de la familia. Además de la familia, se desarrollan también funciones primarias y ponen en marcha estructuras específicas de solidaridad otras sociedades intermedias. Efectivamente, éstas maduran como verdaderas comunidades de personas y refuerzan el tejido social, impidiendo que caiga en el anonimato y en una masificación impersonal, bastante frecuente, por desgracia, en la sociedad moderna.» (C.A. 49).

\section{5. «Caritas in Veritate»: ¿un aporte nuevo en la Doctrina Social de la Iglesia (DSI)?}

El día 29 de junio del 2009 el papa Benedicto XVI firmó su carta encíclica Caritas in veritate (la caridad en la verdad. Sigo la edición de la editorial S. Pablo, Madrid 2009) sobre el desarrollo humano integral, en la línea de lo que fue la encíclica de Pablo VI, «Populorum progresio». Este documento aparecía en medio de una de las crisis financieras mundiales más importantes de todos los tiempos. Y, junto a lo anterior, que ya es importante, estaban los graves problemas sociales asociados a la globalización, la inmigración, el desarrollo de la bioética y sus implicaciones éticas, y así un conjunto de nuevas y complejas realidades que exigían una palabra de parte de la iglesia en su doctrina social.

Por tanto, esta encíclica que quiere ser una palabra de humanismo, luz y de esperanza en clave cristiana ante tan grandes y acuciantes desafíos, no tiene una preocupación económica directa, ni mucho menos entra en temas de plantear «políticas económicas» (como no lo ha hecho nunca la DSI). «La iglesia no tiene soluciones técnicas que ofrecer y no pretende de ninguna manera mezclarse en la política de los Estados. No obstante, tiene una misión de verdad que cumplir en todo tiempo y circunstancia a favor de una sociedad a medida del hombre, de su dignidad y vocación» (p. 18). 
¿Por qué tal título? Dice el Papa " "Caritas in veritate" es el principio sobre el que gira la doctrina social de la iglesia, un principio que adquiere forma operativa en criterios orientadores de la acción moral. Deseo volver a recordar particularmente dos de ellos, requeridos de manera especial por el compromiso para el desarrollo de una sociedad en vías de globalización: la justicia y el bien común» (p. 13).

Cito textualmente un párrafo del capítulo III, donde se hará una referencia más directa a los asuntos económicos, y que a modo de síntesis podría resumir el núcleo de la encíclica: «En este caso, caridad en la verdad significa la necesidad de dar forma y organización a las iniciativas económicas que, sin renunciar al beneficio quieren ir más allá de la lógica del intercambio de cosas equivalentes y del lucro como fin en sí mismo» (p. 77).

El Papa no «condena» el capitalismo (sería bastante anacrónico), ni siquiera habla de alternativas al mismo. Lo asume como la forma de organización económica, política y cultura que tenemos. Sin embargo, constata que la crisis (desigualdades, problemas con el desarrollo, enriquecimiento ilícito, etc.) son producto de una falta de valores éticos sólidos que puedan fundamentar una acción económica en sentido amplio en el marco del mercado.

Es verdad que por momentos sus planteamientos se mueven más a favor de la política, diríamos del intervencionismo, asignándo a los Estados e instituciones un papel decisivo en la solución de los problemas globales, de ahí muchas críticas que tuvo de sectores «liberales»; también habla de «justicia distributiva». Y en otros le da un papel relevante a la «sociedad civil» — nos imaginamos piensa en las ONG de raíces cristianas- como la vía necesaria para hacer un mundo más justo.

El capítulo VII, otro de los más notables en clave económica, dedicado a la técnica, sigue su desarrollo en la misma línea que el anterior: «El desarrollo es imposible sin hombres rectos, sin operadores económicos y agentes políticos que sientan fuertemente en su conciencia la llamada al bien común».

Para esta encíclica, economía y desarrollo se resuelven en última instancia en valores éticos trascendentes previos que pueden impulsar de manera coherente la riqueza y el bienestar que nos da el mercado. Por eso, considero que no sería justo hablar de un 
«retroceso» respecto de Centessimus annus, sino más bien de profundizar de manera antropológica y teologal en temas económi$\cos$, queriendo establecer un equilibrio entre todos los actores del proceso social: ciudadanos, empresarios, Estado, políticos, sociedad civil, etc.

\section{II \\ VALORACIÓN A LA CRISIS DE LA CIVILIZACIÓN}

El malestar por la cultura del momento no sólo es una preocupación del magisterio eclesiástico, sino también de una serie de corrientes filosóficas y políticas que hoy tienen amplia repercusión en el momento cultural que nos toca vivir.

No olvidemos que el liberalismo austriaco es sólo una rama del liberalismo contemporáneo, junto a otros liberalismos, como el de Escuela de Chicago, de la Escuela de Friburgo o de la Escuela de Virginia. Hablaré de dos movimientos «neo liberales» (pero mi explicación estará sólo en función de los aportes de la Escuela Austriaca).

\section{1. ¿Uno o varios liberalismos?}

Necesitamos hacer una necesaria purificación del lenguaje político, y la primera clarificación es delimitar el concepto liberalismo, cuáles son sus auténticos postulados y cuáles sus diferencias más importantes respecto a otras corrientes filosóficas hoy.

La primera distinción que quieren dejar claro es de la ambigüedad de contenidos que hoy expresa la palabra «liberal». En USA o en Canadá, por ejemplo, liberal es aquél que cree en la intervención creciente del Estado en economía, promociona políticas redistributivas; en moral deja un amplio campo de experimentación individual en temas como el aborto, la familia, la homosexualidad, etc.; el liberal americano sería más bien el social demócrata europeo. Dice R. Dahrendorf, «El cuadro del liberalismo actual es extraordinariamente confuso: en Australia los conservadores se llaman; en Canadá, los socialdemócratas; en Italia, el 
partido liberal se ha mantenido aferrado a un viejo liberalismo de privilegios y de notables, hasta casi la autoinmolación...La realidad ofrece aquí escasos puntos de apoyo para el análisis por lo que cobra sentido el recurso a la teoría pura; con lo que se confirma el escepticismo de Hayek, según el cual el liberalismo ("por ahora", como dice de modo enternecedor) "supone un movimiento intelectual antes que político".. ${ }^{6}$

Si la identidad del liberalismo por la «izquierda» se confundiría con políticas social-demócratas, por la derecha se confunde con el conservadurismo, «que sólo puede entender el cambio como algo orgánico y en consecuencia como algo marginal y sin orientación.» ${ }^{7}$ En conclusión el liberalismo moderno tiene que recuperar su «verdadera» tradición de ser una ideología de progreso con unas alternativas políticas y culturales distintas de las dos grandes filas ideológicas que hoy siembran el espectro político. «En el aspecto moral, el liberalismo descansa sobre la convicción de que lo importante es el individuo, la defensa de su integridad, de la ampliación de sus posibilidades vitales... En consecuencia, la sociedad tiene que empezar a crear ámbitos de acción, por liberar fuerzas, que, en último término son fuerzas de los individuos. Este es el lugar para conceptos como Estado de Derecho y economía de mercado.» 8

Lo anterior quiere mostrarnos que el análisis, respuestas y propuestas políticas a los problemas que enfrenta la sociedad actual, realizados por el liberalismo moderno, pretenden ser propios y no reducibles a otros métodos de análisis.

Aclarado lo anterior debemos preguntarnos, ¿cuáles son las raíces de la crisis de modernidad? ¿Cuáles son las raíces del liberalismo tradicional? ¿En qué medida los análisis a la crisis cultural son coincidentes con los realizados por el magisterio? Veámoslo a continuación.

6 «Liberalismo» en R. Dahrendorf, Oportunidades vitales. Notas para una teoría social y política, Espasa Calpe, S.A., Madrid 1988, p. 133.

7 R. Dahrendorf, p. 132.

8 R. Dahrendorf, p. 132. 


\section{La Respuesta de la Escuela Austriaca}

El programa de investigación austriaco también ha realizado una importante labor de estudio histórico en el campo de las ideas políticas, a fin de buscar dónde se encontrarían las auténticas raíces del liberalismo y el por qué a esta filosofía se la ha visto fracasar, no sólo desde el rechazo a muchas de sus intuiciones originales, si no que también a nivel de su legitimación ideológica.

\section{a) Los grandes «educadores» de Occidente}

Ante la situación de crisis en que nos encontramos, los teóricos austriacos se preguntan: ¿Qué caminos ha seguido Occidente para llegar a esta situación aparentemente sin salida? ¿Quiénes han sido los grandes maestros desde donde han bebido las élites intelectuales? La clave nos la aportará Hayek, quien nos dirá que Occidente ha fracasado pues ha seguido exactamente el camino contrario a los grandes principios que quisieron los pensadores liberales clásicos. Los grandes maestros de este siglo han sido Rousseau, Marx, Freud, el positivismo filosófico y toda forma de racionalismo cartesiano que ha erosionado los principios morales desde donde se edifica la sociedad. Los ideales del humanismo renacentista mediados por la influencia del cristianismo, como las ideas de D. Hume, I. Kant, A. Toqueville, A. Smith, E. Burke, etc., han sido plenamente olvidadas. La crisis no es de liberalismo sino, paradójicamente, de que la civilización lleva caminando casi más de un siglo con unos presupuestos filosóficos y culturales que no responden en nada a los principios originales de esta filosofía. Dirá Hayek: «Abordaré, finalmente, un tema que durante muchos años ha producido en mi ánimo gran alarma y preocupación: la progresiva destrucción de valores sociales irremplazables a manos del error científico...Reciben dichos ataques notable apoyo del hecho de haberse aceptado a nivel intelectual ciertos errados planteamientos en el campo de la filosofía, la sociología, el derecho y la psicología. En las tres primeras disciplinas citadas, los errores derivan fundamentalmente de la influencia 
que en ellas ha tenido el cientifismo cartesiano y el constructivismo de Augusto Compte.» ${ }^{9}$

En otra parte Hayek habla de la moralidad que sustentaba uno de los más destacados economistas de este siglo cuyas repercusiones han sido inmensas, J.M. Keynes, quien en una charla titulada «Mi pensamiento juvenil» dada en 1938, decía:

\begin{abstract}
Repudiábamos por completo la moral establecida, así como todo tipo de convención derivada del saber tradicional. Estábamos, pues, en el sentido más estricto del término contra la moral..No reconocíamos la existencia de obligación moral alguna ni sanción íntima que pudiera servir de guía a nuestro comportamiento. Reivindicábamos ante el cielo y la tierra el derecho a ser jueces únicos de nuestra propia causa. ${ }^{10}$
\end{abstract}

\title{
b) Las dos tradiciones del liberalismo
}

La Escuela Austriaca, desde el análisis de las fuentes históricas, le dirá a la Iglesia que cuando ella ha hablado de liberalismo, y en el siglo pasado lo ha condenado, ha sabido tener en cuenta, primero, los aportes fundamentales que esta filosofía de la libertad ha hecho al desarrollo de la civilización: el progreso científico, la concepción jurídica de los derechos, el progreso económico, el intento de fundamentar un pluralismo de visiones del mundo, etc., como a su vez, la misma transformación que en su interior se ha producido. Pero sobre todo, ha sabido distinguir cómo dentro de una misma filosofía hay tradiciones tan diversas, el racionalismo constructivista continental y el racionalista evolutivo anglo-sajón como repetidamente ha puesto de manifiesto F.A. Hayek, y en el campo católico M. Novak, al punto de tener posturas respecto de las instituciones sociales, del derecho, la moralidad y las tradiciones, irreconciliables. ${ }^{11}$

\footnotetext{
9 Hayek, Law, T. III., p. 173.

${ }^{10}$ Citado por Hayek en Law, T. I., p. 26

11 Hayek esto lo explicará en diversos sitios, puede verse su artículo «Liberalism», en New Studies. También M. Novak, Freedom with Justice. Social Thought and Liberal Institutions, Harper \& Row, S. Francisco 1984.
} 
Es verdad que ambos liberalismos exaltan la libertad —sólo este tema puede dar lugar a una tesis- pero no ambos de la misma forma. El Austriaco cree en la sabiduría de normas morales que no pueden ser alteradas a capricho de nadie, pues allí reside la posibilidad de una convivencia civilizada, punto distinto es si la fundamentación a posteriori de Hayek convenza no sólo a católicos, sino a los mismos liberales que en principio no compartan convicciones religiosas.

\section{c) El desprecio de la ley}

Otro hecho, relacionado con lo anterior, estaría en que moralistas y juristas en general, y teólogos en particular, constatan el creciente menosprecio por la ley. Pocas personas son las que relacionan el cumplimiento de ésta con la honradez moral o con la justicia, es más, muchas veces la moralidad estaría en no cumplirlas. Nos dicen los austriacos: ¿No habremos sido conducidos por el constructivismo jurídico, que al igual que el planificador socialista del debate de Mises, cree que puede hacerse con la información de la sociedad y legislarla vía mandatos, como brillantemente lo señalara el jurista italiano B. Leoni? ¿Qué parte de responsabilidad en la desmoralización de la sociedad le queda al Estado Social que en su afán de mejorar el orden social -empresa imposible desde el paradigma austriaco- hace uso de la situación de privilegio, generando un caudal de reglamentos y leyes que nadie puede seguir, ni tan siquiera conocer? ¿O qué relación guarda la creencia en un democratismo radical - denunciado tanto por Hayek como por la Iglesia- de que todo es sometible a votación, y que donde las mayorías vencen puede esto o aquello hacerse ley, sometiendo las conciencias de los ciudadanos? ${ }^{12}$ Nos recuerdan los austriacos: una democracia auténtica descansa no sobre la «soberanía popular» sino en la «soberanía de las leyes» expresiones éstas de auténtica libertad.

12 A este respecto puede verse el artículo del Prof. Jesús Huerta de Soto, «El Fracaso del Estado Social» en Estudios de Economía Política, Unión Editorial, Madrid 1995. 


\section{El nexo entre Democracia y Capitalismo: una relación no vista por la DSI}

Hemos visto que la DSI poco a poco ha ido reconciliándose con un tipo de democracia fundamentada en la defensa y promoción de los derechos humamos. Nos señalan estos movimientos que el magisterio, y muchos otros teóricos del capitalismo, no han visto con la suficiente claridad el nexo que históricamente se ha dado entre capitalismo y democracia, pues ésta sólo se ha desarrollado en regímenes que asumen economías de mercado, y no en otros tipos de economía.

Recordemos que uno de los reproches clásicos del marxismo, y en general de toda la izquierda, es que el liberalismo proclama lo que no cumple. Habla de libertades formales, pero que en la práctica no son más que ficciones o argucias jurídicas, puesto que están al servicio de los que poseen el capital; es verdad que somos iguales, pero en la vida real, altamente desiguales, puesto que desde el nacimiento arrastramos diferencias sociales que a lo largo de nuestra historia sólo se perpetúan. Tras la fachada de la democracia se esconden los privilegios de los de siempre. Democracia y capitalismo son incompatibles, si queremos uno estamos obligados a negar el otro.

Nuestros teóricos retoman el planteamiento del problema y lo reinterpretan llegando a conclusiones totalmente opuestas. En la prehistoria de este análisis están dos obras de carácter altamente divulgativas, pero que sin embargo abrieron nuevos cauces para el debate, Capitalismo y libertad de M. Friedman y Camino de Servidumbre de F. von Hayek. El argumento central del primero descansaba sobre la base de que hemos podido hablar con rigor de libertad cuando ha advenido el mundo capitalista, el cual transformó las estructuras feudales y mercantilistas posibilitando la libertad de movimiento, tanto de ideas, de hombres y de capital. El segundo sostiene que los máximos logros de occidente se deben al ideal de libertad que vino de la mano del liberalismo, este ideal, siempre frágil de conservar, se encuentra amenazado con la difusión de ideas socialistas que tras la retórica de la justicia social intentan conscientemente dirigir nuestras vidas mediante la intervención creciente del estado social en todos los ámbitos de 
la sociedad. Nos advierte, que en cada recorte de nuestra libertad económica estamos entregando nuestra libertad política, o lo que es lo mismo, no existe libertad política sin libertad económica.

Dice Hayek,

$\mathrm{Al}$ menos durante los veinticinco años anteriores a la trasformación del espectro del totalitarismo en una amenaza real, hemos estado alejándonos de las ideas esenciales sobre las que se fundó la civilización europea... Hemos abandonado aquella libertad en materia económica sin la cual jamás existió libertad política. (F. von Hayek, Camino de Servidumbre, p., 40, Alianza Editorial, 1976).

Y M. Friedman afirma,

La libertad económica es un requisito esencial de la libertad política... el sistema de mercado compensa cualquier concentración que pudiera producirse. La combinación de poder político y económico en las mismas manos es una fórmula segura para llegar a la tiranía. (M. Friedman, Libertad de elegir, p. 17., Grijalbo, Barcelona 1992).

A partir de estos dos trabajos toda una serie de autores quieren reencontrar las raíces clásicas de la democracia liberal, en contra de un tipo de democracia social que ha ganado adeptos y se ha concretado en línea de acción del Estado moderno. En este siglo esto ha sido posible gracias al auge del socialismo democrático.

Para ellos el capitalismo es inseparable de la democracia. En países sin una tradición democrática fuerte, en un primer momento pudieran estar no unidos, quizás en regímenes autoritarios, pero la misma dinámica de libertad económica exigirá tarde o temprano la libertad política. Ahora bien, lo que es claro es que todos los regímenes que son democráticos tienen economías capitalistas, y eso sin excepción. Querer suprimir una libertad a costa de potenciar la otra, es un sin sentido. Es completamente falsa la dicotomía «o pan o libertad». La libertad es indivisible. 


\section{4. ¿Existen puntos de encuentro entre la DSI y el neo-liberalismo en su diagnóstico cultural?}

Ambos coinciden en percibir una crisis cultural profunda. Junto a esto también habría que decir que la preocupación original desde donde se quiere descubrir, analizar y proponer soluciones a la crisis es distinta. El neo-liberalismo intentará «salvar» un sistema económico que se ve cerca del colapso por culpa de una crisis cultural. Por su parte, la DSI quiere buscar las condiciones sociales que dignifiquen al hombre, es decir, si habla de economía es porque descubre que en ella se está jugando la dignidad del ser humano, su preocupación es antropológica. Por tanto, no parte a priori de la bondad o maldad de ningún sistema; su eficacia económica o la posibilidad de humanizar o no, será siempre una reflexión posterior. Juan Pablo II dirá en Sollicitudo rei socialis 41 respecto a la DSI «En efecto, no propone - la Iglesia - sistemas o programas económicos y políticos, ni manifiesta preferencias por unos o por otros, con tal de que la dignidad del hombre sea debidamente respetada y promovida y ella goce del espacio necesario para ejercer su ministerio en el mundo.»

Ambas doctrinas coinciden en algo importantísimo: sin un «ethos» cultural, una moralidad de virtudes y un Estado de Derecho el capitalismo como organización política y social no puede subsistir. Si falta algo de lo anterior o bien se produce una especie de ley de la selva, o inevitablemente éste entra en contradicciones consigo mismo. En este sentido la respuesta a la crisis cultural propuesta por Juan Pablo II cada vez se va clarificando más: sin la religión, o sin un Dios, que posibilite la incondicionalidad del deber, no existe moralidad posible que asegure el cumplimiento de los derechos del hombre, a este respecto Veritatis Splendor es un buen exponente de lo que estoy diciendo.

Neo conservadores y neo liberales coinciden en un deseo de recuperar el «ethos» perdido que es tanto como encontrar una ideología que sea capaz de justificarlo ante todos. Llaman a que sus defensores no sólo muestren sus virtudes económicas, sino también las político-morales, como su relación con la democracia. Además, mostrar que el capitalismo lleva en su seno la relación comunitaria pues busca la libre asociación tanto en la transacción 
económica como en la cultural. El asociacionismo, o las llamadas «organizaciones intermedias», florecen allí donde los hombres son libres para tomar sus propias decisiones.

Me parece que la DSI puede tomar estos análisis como propuestas de reflexión plenamente válidas de las causas que ellos ven como originantes de la crisis de la modernidad. Algo más difícil es confiar todas sus soluciones al mercado -Escuela Austriaca- o poner a la religión como soporte ideológico de un sistema económico y político neo-conservador.

III

UN DIÁLOGO CON F.A. HAYEK ACERCA DE LA JUSTICIA SOCIAL Y LA SOLIDARIDAD

Hayek, como hemos visto, dedicó toda su vida a combatir el ideal socialista como forma de organización social. A su vez, vio en los términos justicia social y solidaridad, encarnadas por todas las formas de socialismo contemporáneo, dos acabadas expresiones de actitudes «atávicas» que ya no responden a las exigencias de un orden extenso de cooperación humana como es el mercado, y que sus aplicaciones a nivel político y económico significarían la ruina del orden de mercado, por consiguiente de la civilización, y con ello la muerte de millones de seres humanos. No olvidemos que el tomo II de su trilogía está dedicado especialmente a mostrar el sin sentido de estos términos, su título El espejismo de la justicia social ilustra todo el desarrollo de la obra.

$\mathrm{Al}$ estar estos dos términos tan presentes en el magisterio eclesiástico no podemos menos que estudiar las diferencias que existen cuando unos y otros está empleando el mismo nombre.

\section{La justicia social y la solidaridad en el magisterio}

De los múltiples temas que ha tratado el pensamiento social de la Iglesia, sin lugar a dudas, el de la justicia social ocupa un lugar eminente. Todos los pontífices de alguna forma se han referido 
a ella y han visto que de su aplicación o incumplimiento se sigue la legitimidad o no del orden social existente.

De todas las variantes que este término ha recibido en la historia del magisterio eclesial propongo la del Catecismo de la Iglesia católica, que dice:

La sociedad asegura la justicia social cuando realiza las condiciones que permiten a las asociaciones y a cada uno conseguir lo que le es debido según su naturaleza y su vocación. La justicia social está ligada al bien común y al ejercicio de la autoridad (1928).

Lo anterior nos lleva a ver la justicia social como un desarrollo coherente y exigido desde los derechos humanos: «debido según su naturaleza». Si tal o cual realidad posibilita un auténtico desarrollo y promoción de los derechos humanos, entonces podemos empezar a hablar de que tal tipo de justicia social sirve al bien común. Juan Pablo II en Redemptor Hominis dice: «Es así como el principio de los derechos del hombre toca profundamente el sector de la justicia social y se convierte en medida para su verificación fundamental en la vida de los organismos políticos» $(\mathrm{RH}$, 17). El giro antropológico es evidente: todo el ámbito social debe girar en torno a la promoción y desarrollo del ser humano.

Conviene también precisar que el concepto de justicia social es más amplio y englobante que otras formas de entender la justicia, desbordando el término de justicia conmutativa que mira siempre al intercambio de bienes y servicios según una determinada apreciación del valor; o al de justicia distributiva que mira más bien a un cierto reparto de riquezas por parte de una autoridad según ciertos criterios. La justicia social quiere ser la virtud que informe todas las relaciones humanas. «De la justicia social se puede decir también que afecta a la relación de todas las obligaciones entre sí, que determina las unas por medio de las otras y las armoniza. Es la virtud que ordena hacia el bien común los actos exteriores de todas las demás.» ${ }^{13}$

13 J.Y. Calvez, La Enseñanza Social de la Iglesia. La economía. El hombre. La sociedad, Herder, Barcelona 1989, p. 66. 
Otro término que también ha sido destacado por el magisterio, aunque no tenga el mismo peso que el anterior en el conjunto de la doctrina oficial, es el de la solidaridad, que la Iglesia fundamenta desde dos niveles. El primero arranca de la común unidad del género humano basada en unos derechos inalienables que le hacen digno de valor, independientemente de su condición social, cultural o religiosa; los hombres por el sólo hecho de ser tales somos hermanos y estamos mutuamente implicados en el destino del género humano. Dice la encíclica Sollicitudo rei socialis: «..se puede señalar ya como un valor positivo y moral, la conciencia creciente de la interdependencia entre los hombres y entre las naciones. El hecho de que los hombres y mujeres, en muchas partes del mundo, sientan como propias las injusticias y las violaciones de los derechos humanos cometidos en países lejanos... es un signo más de que esta realidad es transformada en conciencia, que adquiere así una connotación moral... Cuando la interdependencia es reconocida así, su correspondiente respuesta, como actitud moral y social y como virtud, es la solidaridad.» (SRS, 38). El segundo es el hecho de la paternidad de Dios en el cual todos somos hermanos, convirtiendo al que tenemos en frente en prójimo «a la luz de la fe, la solidaridad tiende a superarse a sí misma, al revestirse de las dimensiones específicas cristianas de gratuidad total, perdón y reconciliación. Entonces el prójimo no es solamente un ser humano con sus derechos y su igualdad fundamental con todos, sino que se convierte en la imagen viva de Dios Padre, rescatada por la sangre de Jesucristo y puesta bajo la acción permanente del Espíritu Santo.» (SRS, 40).

Ambos conceptos así expresados ¿expresan la misma realidad que aquella a que tan dura crítica Hayek somete?

\section{La crítica a la justicia social y a la solidaridad en Hayek}

No vamos a repetir lo dicho acerca de estos temas tratados anteriormente. Sólo recordar que si queremos entender las razones que llevan a Hayek a realizar semejante afirmación debemos volver sobre los postulados básicos en que descansa la formación y el funcionamiento del orden espontáneo, entre ellos el mercado, 
como el resultado no previsto por nadie, coordinándose en su interior una serie de decisiones cuyas consecuencias nadie puede prever ni mucho menos controlar. Por eso, querer imponer un patrón basado en criterios determinados por un órgano central que mida la justicia es un sin sentido. Aceptados los postulados originales de Hayek vemos que su crítica de la justicia social es coherente con su planteamiento de partida. Tampoco debemos olvidar lo que sugerimos acerca de la responsabilidad que tienen las autoridades de velar por la implementación de aquellos bienes y servicios donde el mercado no llega.

¿Están la DSI y Hayek hablando de lo mismo cuando emplean la expresión justicia social? Pues hay que decir rotundamente que no. Hayek piensa en una especie de planificación de la sociedad que quiere asignar desde arriba bienes y servicios prescindiendo de la libertad humana; o quizás en un Estado Redistribuidor que se arroga el monopolio de producir o intervenir en la vida económica según le parezca oportuno. Hayek, como sabemos, dedicó toda su vida a combatir ambos males, pues presuponía que tarde o temprano este procedimiento acabaría con la libertad individual, haciendo colapsar a la sociedad en su conjunto. Esta «obsesión» le hizo no comprender que, por ejemplo, cuando la DSI está hablando de justicia social no se está pronunciando a priori a favor de una intervención o planificación por parte del Estado sino que habla de aquellas condiciones que posibiliten una vida digna; si algo expresa este concepto es, ante todo, una realidad moral, pues ella es la que debe presidir la vida social en su conjunto, y no solo la relación del hombre y el Estado. En este sentido estamos plenamente de acuerdo con la afirmación de J.I. Calvez cuando dice «debe observarse a este propósito que Hayek confunde expresamente la justicia social de la enseñanza social de la Iglesia con una especie de distributismo o una justicia igualitaria de resultados y que, por tanto su crítica de esta enseñanza social no llega al núcleo del problema. Imputa a la Iglesia un igualitarismo del que ésta siempre ha pretendido mantenerse alejada.» ${ }^{14}$

${ }^{14}$ J.I. Calvez, p. 66. No obstante, podría decirse en descargo de Hayek que él crítica el concepto más popular (incluso a nivel académico) de justicia social, que como vemos no coincide con la Justicia Social tal y como la concibe la Iglesia Católica. 
Lo mismo habría que decir con el concepto de solidaridad. Cuando uno u otro están hablando de solidaridad le están dando un contenido diverso. Para Hayek solidaridad expresa los lazos de dependencia producidos por el hecho del nacimiento en un mismo contexto, llámese tribu, y que por tanto exige una moralidad de obligaciones recíprocas entre los miembros del mismo clan, hecho que ya no es posible con el advenimiento de la «Gran Sociedad» por las características antes señaladas. La DSI tiene un concepto universalista de dependencia de los unos para con los otros en razón de la condición humana y, leída en clave cristiana, sobrenatural. Ella maneja ante todo un concepto jurídico-moral y teológico, por tanto «metafísico» y especulativo de solidaridad, tratando de fundamentarla desde: la naturaleza humana, la dignidad, los derechos del hombre, la vocación sobrenatural, etc., concepto muy alejado de una unidad fundamentada en lazos sanguíneos, propios del orden tribal. Lo dicho con respecto a la justicia social se aplica también al tema de la solidaridad: la crítica de Hayek es a un concepto que no guarda relación con el que maneja la Iglesia. Ambos hablan lo mismo pero no de lo mismo.

\section{La aportación de M. Novak al debate en torno a la Justicia Social}

Por lo importante del tema vamos a presentar brevemente a un liberal-católico, M. Novak. ¿Quién es? Es un teólogo católico americano que ha intentado desde su análisis doctrinal establecer el puente entre la moral católica y el liberalismo político económico. Todo lo dicho acerca del neo-conservadurismo americano arriba estudiado se aplica a él.

\section{a) La necesaria relación entre ethos cultural y economia}

Las fuentes donde conscientemente se sitúa es M. Weber y la interpretación que éste hace de la religión en el proceso de secularización y de nacimiento del mundo moderno, el cual lo ve inseparable de La ética protestante y del espíritu del capitalismo, es decir, 
la religión ha jugado y sigue jugando un papel decisivo en la configuración del mundo moderno. ${ }^{15}$

Novak nos plantea la pregunta ¿es separable el ámbito económico del político-cultural?, y la respuesta es no. Siguiendo a D. Bell ve la sociedad estructurada sobre tres subsistemas: político, cultural y económico, ambos independientes en sus desarrollos pero a su vez mutuamente implicados. El capitalismo al descansar sobre la libre iniciativa de los seres humanos necesita de un orden plural donde se respeten los derechos de los individuos, gestando instituciones para tal efecto, de ahí que sólo en regímenes con economía capitalistas se hayan respetado los derechos individuales y fortalecido las instituciones democráticas. El capitalismo en su mismo desenvolvimiento reclama la posibilidad de asociarse a los otros, generando de esta forma lo que gusta en llamar un «individualismo comunitario». La invención propiamente capitalista es la empresa, que como célula comunitaria, da la posibilidad de trabajar unidos bajo una meta común.

La economía depende de los sistemas morales-culturales, si estas virtudes faltaran, el colapso económico sería evidente. La democracia, a su vez, reclama de la ética cristiana: la conciencia individual, la noción de pecado - tan importante para concebir la separación y equilibrios de poderes- la idea de perfectibilidad, de valor de los actos dados, el valor de la libertad como posibilidad de apertura al futuro, y la naturaleza social del ser humano.

\section{b) La justicia social en el ámbito del capitalismo democrático}

Otro punto importante es el retomar el tema de la riqueza y mostrar, en contra del marxismo, cómo ésta no es fruto del robo, sino de la inteligencia, de la percepción de oportunidades, y sobre todo, de esos hábitos que él alaba: el ahorro, el sacrificio, la perseverancia, fruto de ese «ethos» cultural sin el cual el capitalismo no puede funcionar. La Doctrina moral católica, nos recuerda el autor,

15 Para este punto es esencial ver su libro clásico M. Novak, The Spirit of Democratic Capitalism, Madison Books, Boston, 1991. 
se ha preocupado más por el tema de la «justicia distributiva», pensando que la riqueza es algo que está en frente nuestro y que con un cálculo matemático podremos asignarla, olvidando el componente creativo que tiene la riqueza, la cual es siempre fruto de la inteligencia. «El modelo actual de la DSI en el presente está más emparentado a una suave forma de socialismo que al capitalismo democrático. Poco ha dicho del mercado y los incentivos, la ética de la producción y de las organizaciones necesarias para la creación de la riqueza. Parece darla por sentado (como si la riqueza fuera tan limitada y estática como en la edad media) y sólo preocupada de la redistribución.» ${ }^{16}$ Pero además la DSI ha olvidado algo fundamental como es el ver que no todas las instituciones políticas y económicas están en igualdad de condiciones en la protección de los derechos humanos y en promoción del progreso económico. Añade que la DSI al hablar de justicia social se mueve en un ámbito de grandes principios, aplicables a muchas épocas, por eso es necesario que entre en política económica y vea cuál posibilita la mejor defensa de la libertad y del progreso. ${ }^{17}$

Novak retoma el tratado de la teología de la creación como fundamento cristiano del capitalismo que en su misma dinámica busca y aprovecha las potencialidades creativas del ser humano. Introduce un nuevo concepto que también debería medir la salud de una sociedad y es la «justicia creativa».

Acerca de la relación catolicismo liberalismo nos dirá:

Ha sido una tragedia tanto para el catolicismo como para el liberalismo su histórica hostilidad. El liberalismo necesita del sentido de comunidad, trascendencia, realismo, ironía, tragedia y mal. Y el catolicismo necesita de las instituciones del liberalismo para la encarnación en la sociedad de su propia visión de dignidad de la persona humana, del indispensable rol del libre asociacionismo y de los límites del Estado respecto a los derechos de la recta conciencia. ${ }^{18}$

\footnotetext{
16 M. Novak., The Spirit, pp. 248-249.

17 M. Novak, Freedom, pp. 25-38.

18 M. Novak, p. 33.
} 
IV

\section{LA ESCUELA AUSTRIACA: TRES APORTES AL ANÁLISIS ECONÓMICO DE LA TEOLOGÍA MORAL}

Las propuestas del liberalismo austriaco pueden convertirse, y ahí ha residido mi deseo de investigación, en un nuevo instrumental analítico para entender ciertos aspectos de la economía de mercado que desde otras escuelas de pensamiento económico no quedan, a mi parecer, suficientemente explicados en una teoría coherente del hecho económico. Los puntos los propongo a continuación.

\section{Beneficios, Función empresarial y Economicismo}

Los apartados anteriores nos pusieron sobre la pista de la relación intrínseca entre conocimiento y economía. Hemos insistido repetidas veces en que el mercado lo que genera y transmite es ante todo información, la que por su misma naturaleza está dispersa, es subjetiva e inarticulable.

Cuando la Doctrina Social ha hablado de beneficios lo ha hecho desde las ganancias monetarias, pero no ha relacionado, porque carece del instrumento de análisis suficiente, beneficio con imperfección del conocimiento, o si se prefiere, con descoordinación social. Repitamos lo que dijimos arriba: el mercado permite obtener beneficios porque es un proceso dinámico de transmisión de información, de percepciones distintas, de conocimientos no acabados de toda la realidad que nos rodea; el beneficio es la posibilidad no descubierta por el otro, fruto de nuestra ignorancia. En un mundo de conocimientos perfectos, donde todos percibiéramos lo mismo, la ganancia sería un sin sentido.

¿Se le abre a la teología moral otro ámbito de reflexión en torno a la moralidad de los beneficios? Me parece que sí y muy importante, porque en un marco legal estable e igual para todos, el beneficio, fruto de la acción empresarial, es la recompensa al descubrimiento de una descoordinación social no prevista - por ejemplo el mal aprovechamiento de un recurso-, permitiendo, y aquí entramos de lleno en la realidad de la acción empresarial, que 
se elimine de la sociedad todo aquello que dificulta su progreso y normal funcionamiento.

El ejercicio de la función empresarial, no sólo es la clave del progreso por su constante tendencia a ver allí donde nadie ha visto, sino que es la función social por excelencia pues es la mediación que descubre y elimina, guiada por el beneficio que como señal abstracta marca hasta dónde es necesaria la acción a desarrollar, todo aquello que perjudica o descoordina la vida social.

La función empresarial nos abre también a la teología otro campo de reflexión pues nos da un horizonte más amplio para poder comprender la naturaleza específica de la competencia, entendida como ámbito de creatividad y descubrimiento en un mundo de conocimientos fragmentarios y de posibilidades inciertas.

Acción empresarial y beneficios son conceptos amplios que podemos cargar de diversos significados. La acción empresarial, como nos recordaba Mises, es una característica del ser humano. En el ámbito donde estemos, según las motivaciones y posibilidades que el entorno nos genere estamos realizando la acción empresarial, cuyos beneficios no tienen porqué ser siempre medidos monetariamente.

Entendida la acción humana así, vemos cómo la DSI puede ampliar su campo de reflexión sobre el hecho económico que hereda tanto de la tradición clásica y neoclásica como del marxismo, centrado en los objetos de la economía, los bienes materiales, y no en el verdadero protagonista de ella: el ser humano.

La función empresarial nos vuelve a plantear otro problema a la teología moral ¿Si es la creación humana ejercida en su función empresarial la clave del beneficio, tiene el hombre derecho íntegro al fruto de su trabajo? ¿Cómo justificar la coacción que con parámetros tan variables se ejerce sobre los ciudadanos? Todas estas preguntas son las que nos pone sobre la mesa la Escuela Austriaca.

\section{2. Órdenes extensos, propiedad privada y crecimiento demográfico}

Otro aporte a nuestra reflexión moral viene dado por la compresión de los órdenes extensos de cooperación humana - como 
Hayek en su última obra denominó al mercado-y éste reside en la posibilidad de realizar un tipo de bien donde «tu mano derecha no sabe lo que hace tu mano izquierda» o lo que es lo mismo, la posibilidad de cooperar con una multitud de hombres que no conocemos ni jamás podremos llegar a conocer. Esto es una forma de expresar la solidaridad - palabra tantas veces empleada por el magisterio- que por lo frío de su abstracción choca con nuestra tendencia a vivir nuestra cooperación con los que nos son más próximos. Cristianamente vemos como irrenunciable nuestra preocupación, fundada en el amor cristiano, por vivir de cara al prójimo, y de hecho la experiencia comunitaria es la más importante y primigenia de nuestra vida cristiana. Pero ¿no tendremos que hacer una autoevaluación y revisar muchos de nuestros esquemas morales que tienen su razón de ser en comunidades pequeñas, y que ya no son extrapolables al ámbito del orden extenso como nos enseñara Hayek?

Recordemos el teorema de la imposibilidad del cálculo económico en el socialismo, debido a que éste prescinde de la propiedad privada de los medios de producción, impidiendo, por tanto, que se formen auténticos precios de mercado. Respecto a la propiedad privada, punto de litigio por excelencia con cualquier forma de socialismo, no he encontrado en nuestros manuales de teología moral, como en los documentos oficiales, mayor explicación o justificación de ésta que la doctrina clásica: la función social de la propiedad y el ámbito de libertad que su posesión implica. Completando las razones anteriores ise nos ha ocurrido relacionar la propiedad con la escasez inerradicable que nos aqueja, por lo tanto debe ser economizada, o también, con la descentralización y creación de nueva información que su uso implica para así ser transmitida al conjunto de la sociedad mediante la coordinación que el mercado posibilita?

Otro punto que merece una atención especial es la relación directa entre mercado y crecimiento de la población. La división creciente del conocimiento requiere del potencial humano capaz de crear y transmitir los volúmenes de información que la sociedad necesita. Es lo que más arriba llamábamos el Big-Bang social que vive en un permanente proceso de retroalimentación o feedback: el desarrollo de la sociedad hace posible el crecimiento de la población, la cual gracias al nuevo conocimiento que se ha generado 
posibilita el desarrollo social, y así de una manera continua. Sería de esperar que este argumento se pudiera conocer mejor en el interior de la moral católica sobre todo cuando nos toca hablar de natalidad y su relación con la pobreza y el subdesarrollo.

Respecto a esto el Prof. J. Huerta de Soto ha señalado: «Lo maravilloso del cristianismo es que nos indica que este Big-Bang expansivo, no es un sin sentido, sino que es querido e impulsado por Dios como hacedor del universo y de la historia. Es una muestra del amor que nos tiene: creced y multiplicaos.»19

\section{Un punto de encuentro: de la teología del trabajo a la teología de la acción humana}

Las notas anteriores nos situaron en torno a los temas claves que maneja la Escuela Austriaca. Hemos visto cómo la acción humana está en el centro de toda su reflexión económica, moral y política. El ser humano se convierte en el verdadero artífice de todo el desenvolvimiento económico. Es él quién crea y concibe nuevos fines desencadenando el proceso económico.

Desde el momento en que ponemos al hombre como centro de todo el proceso económico, es decir, de la función empresarial llevada a cabo por éste, nos estamos alejando de la economía neo-clásica y maximizadora - referencia obligada que tienen los teólogos moralistas cuando hablan de economía- marcada por la matematización de todo el entramado económico, y la consideración de la información y el acontecer futuro como algo dado y objetivo.

Ciertamente la teología, y cualquier otra ciencia que se preocupe de la actividad humana, tendrá poco margen para la reflexión, pues en esos grandes gráficos de imaginarias curvas de oferta y demanda, o en las grandes cifras del producto, inflación, costes y beneficios, fundamentados en sofisticados instrumentos matemáticos, cualquier reflexión humana o queda diluida ante la

19 Agradezco al Prof. Jesús Huerta de Soto esta profunda reflexión teológica, que se hace aún más significativa al provenir de un economista como él. Sobre el BingBang social debe consultarse su obra Socialismo, cálculo económico y función empresarial, 4. ${ }^{\text {a }}$ edición, Madrid 2010, especialmente capítulo 2 y p. 79n. 
imposibilidad de reconocerse ahí o simplemente la moral tiene la posibilidad de hablarnos de un «hombre económico» (algunos lo denominan productor-consumidor) que sólo vive en el estrecho margen de la racionalización y optimización de sus recursos.

Me parece que la mediación se debe centrar en la subjetividad del trabajo, según Juan Pablo II, o en la acción humana según la Escuela Austriaca. Aunque a veces la encíclica tiende a separar trabajo de capital, introduciendo una dicotomía que a algún autor austriaco no gustaría, pues éste no es separable del sujeto que lo concibe y que por tanto merece el fruto de su esfuerzo creativo, tanto en las ganancias como en las pérdidas.

Tomando como punto de partida a la antropología católica, la cual parte de un hecho dogmático: el hombre es el centro de todo lo creado, y todo queda subordinado a él. Él es el único ser sobre la tierra capaz de iniciar y prolongar a lo largo de su historia un diálogo de amor con Dios. En definitiva, el hombre es imagen y semejanza de Dios, el cual a lo largo de su historia va sometiendo mediante su trabajo y esfuerzo todo el universo, colaborando en la creación originaria de Dios.

El trabajo, nos recordaba el papa en la Laborem exercens (67), nace de la subjetividad humana. Gracias a la aplicación de la inteligencia del hombre, de sus talentos y habilidades, el trabajo tiene la dignidad que se merece. El trabajo deviene humano no porque sirve a la satisfacción de necesidades o por la transformación que hacemos de la naturaleza - acciones que a su manera también la realizan los animales- sino ante todo porque nace de la capacidad creativa del ser humano que mediante su inteligencia constantemente actualiza la obra de Dios (53).

El trabajo como fruto de la inteligencia y de la voluntad humana encuentra en esa misma subjetividad su dignidad, sin importar sus creencias, cultura, o condición social. Ahora bien, esa realidad vivida desde la dimensión teologal: fe, esperanza y caridad, es para el creyente ámbito de encuentro con Dios, posibilidad de salvación y realidad donde se gesta la fraternidad cristiana en la construcción de un mundo más humano.

En la encíclica Centesimus Annus (32) el Papa da un paso más y muestra como la capacidad creativa del hombre, expresada en su conocimiento, se está convirtiendo en decisiva para la vida 
sociedad, produciéndose un salto cualitativo respecto a la precedente doctrina económica.

En el campo de la teología católica ${ }^{20}$ dos líneas de reflexión - por lo menos que yo conozca- se están desarrollando; una es la de M. Novak, que intentará fundamentar el ethos del capitalismo, confesándonos que tras años de investigación ve que el núcleo de esta filosofía económica reside en su capacidad creadora, pues sólo ésta puede posibilitar, en el interior del sistema moral y político del liberalismo, el marco adecuado para el desenvolvimiento del ser humano. Él retoma, como hemos visto, el tratado de la teología de la creación, mostrándonos cómo el camino de la teología católica queda abierto a un horizonte más amplio de reflexión una vez que hayamos comprendido el núcleo principal del capitalismo. Recordemos que incluso llega a sugerir que se introduzca otro término para medir la justicia de una sociedad y es el término «justicia creativa». La otra, es la obra de B. Lonnergan (enseñó al inicio de su carrera economía en Harvard) quien desde una notable reflexión filosófico-teológica nos hablará del universo como una emergent probability donde la acción del hombre mediante el discernimiento o perspicacia - utiliza la palabra insightdescubre las potencialidades que allí se esconden. El futuro es un horizonte abierto e inacabado, ámbito de los insight del ser humano, el cual con su acción libre puede transformar la realidad abriendo horizontes llenos de posibilidades o cerrar el futuro para siempre; no existe una historia preestablecida hacia la cual la humanidad marcha inexorablemente. Visto lo anterior en clave religiosa, nos dirá: la creación es una realidad inacabada y los seres humanos deben completar la obra del creador.

¿Cuál es el camino que Dios ha establecido para que los hombres podamos utilizar el trabajo de todos y así beneficiarnos mutuamente? Como era de esperar, la revelación no da respuesta a esto. Aquí entra ya la experiencia histórica que los hombres a lo largo del tiempo van adquiriendo. La preocupación que tiene el magisterio a este respecto se mueve a nivel de principios, que

20 Sigue siendo un libro de referencia obligatoria M. Novak, The Spirit of Democratic Capitalism, Madison, New York, 1990 y el de B. Lonnergan, Insight: A study of Human Understanding, New York, 1958. 
iluminados por la revelación divina nos hablan de todas aquellas condiciones de vida que mejor favorezcan la dignidad humana, de aquél que es llamado a la perfección humana y sobrenatural.

¿Puede servirnos la explicación Austriaca de los procesos sociales? Me parece que sí, pues nos abre un camino de explicación para entender cómo se crea y coordina la información necesaria para el sostenimiento de la sociedad y cuáles son las implicaciones éticas que se siguen de su alejamiento.

\section{$\mathrm{V}$ \\ CONCLUSIÓN. UNA NUEVA CLAVE MORAL PARA ENTENDER EL HECHO ECONÓMICO: HACIA UN HUMANISMO INTEGRAL}

Los obispos americanos, preocupados por la situación económica que vivía su país y sensibles ante los nuevos caminos que estaban tomando las políticas económicas aplicadas en aquella década, redactan en el año 1986 una carta pastoral titulada, Justicia económica para todos, donde definirán su postura como pastores ante tal situación y las razones que les mueven a posicionarse en tales ámbitos.

Se preguntan cuál ha de ser el criterio que sirva para juzgar la acción económica, y afirman: «Toda decisión o institución económicas deberá ser juzgada de acuerdo con su capacidad de proteger o menoscabar la dignidad de la persona humana. El punto de partida de la carta pastoral es la persona humana. Creemos que la persona es sagrada —el más claro reflejo de Dios entre nosotros-. La dignidad humana no proviene de la nacionalidad, raza, sexo, nivel económico o cualquier capacidad humana, sino de Dios... La economía debe servir a la gente y no al revés.» $(\mathrm{JE}, 13)^{21}$

21 Esta idea es la ampliación de la ya propuesta por el Concilio Vaticano II en su constitución Gaudium et Spes n.. 63 , donde dice: «También en la vida económicosocial deben respetarse y promoverse la dignidad de la persona humana, su entera vocación y el bien de toda la sociedad. Porque el hombre es el autor, el centro y el fin de toda la vida económico-social». 
La cursiva en el texto anterior pertenece al original, pues se quiere dejar en claro que la preocupación de los obispos no se mueve en el plano de las discusiones técnicas que enfrentan a distintas escuelas económicas, afirmarán más adelante que el campo de investigación en ese ámbito queda plenamente abierto - véase el número 135 - si no a nivel humanista, preocupados porque la dignidad de la persona humana no se degrade.

El criterio antes expuesto refleja claramente por qué el magisterio ha hecho de la «cuestión social», y de la economía como un elemento importantísimo en nuestra sociedad, su preocupación permanente. Más allá de la vieja polémica entre capitalismo y socialismo, la verdadera pregunta de discernimiento que a lo largo de más de un siglo se ha estado haciendo el magisterio es: qué organización económica-política posibilita el desarrollo del ser humano como imagen de Dios; su reflexión tampoco se ha quedado a nivel interno de sociedades que ya habrían alcanzado un grado de desarrollo sino que lo ha ampliado a nivel internacional, sabiendo que no existirá verdadera paz en el mundo mientras existan las desigualdades económicas que hoy aquejan a la humanidad, la Populorum Progressio es un buen ejemplo de esto.

El magisterio, junto con afirmar la autonomía de las realidades terrenas y la legitimidad del uso de su propio método de investigación en los asuntos económicos, ha manifestado que esta realidad no puede vivir al margen de las repercusiones humanas que de su aplicación se derivan. La justicia social se convierte en el gran referente para enjuiciar la acción política y económica en su conjunto. Como dicen los obispos americanos «El concepto de la justicia social abarca también el deber de organizar las instituciones económicas y sociales de tal forma que respeten la libertad y la dignidad de las personas humanas mientras las mismas hacen su aporte a la sociedad.» (JE, 72).

\section{Un necesario discernimiento}

Llegados al final de este trabajo nos preguntamos: ¿Es compatible el liberalismo económico con la DSI? la respuesta quisiera razonarla un poco teniendo como referencia todo lo dicho en este trabajo. 


\section{a) Las fuentes del liberalismo}

La respuesta que demos acerca del liberalismo pasa por la pregunta previa: ¿qué expresión del liberalismo estamos manejando? Porque, como hemos visto, aún existiendo puntos de contacto entre las diversas corrientes, existen también diferencias significativas, además de ser una teoría política y económica en constante evolución. Por eso nuestra primera labor como teólogos ha de ser de discernimiento crítico de las fuentes que estamos manejando a la hora de conocer y, sobre todo, de opinar acerca de esta filosofía política y económica. Me atrevería a decir, y esto sólo lo digo como hipótesis de trabajo, que muchos de los que han hablado de liberalismo lo han hecho desde lo que les han contado que es el liberalismo y no de lo que han dicho los mismos liberales. Lo anterior no implica la posibilidad de que aún conociendo las diversas fuentes y tradiciones alguien pueda ver incompatibilidad entre cristianismo y liberalismo; nuestra libertad moral y la capacidad de interpretación están ahí.

\section{b) La moralidad del mercado}

La relación moral-economía ha sido y seguirá siendo uno de los grandes problemas que ambas disciplinas deben enfrentar e intentar articular. Después de lo visto acerca de la importancia de las normas morales en la Escuela Austriaca y del ethos cultural en el neoconservadurismo, ya no estamos autorizados a hablar de que el capitalismo no tiene «moral». El punto de discusión desde la ética filosófica y desde la teología moral puede ser: tal tipo de moralidad es integrable dentro de la moralidad cristiana. $\mathrm{O}$ tal vez: ¿no será la moralidad del capitalismo un desarrollo coherente del ethos cristiano? También la pregunta puede ser: ¿nos satisface la fundamentación que de ella se hace y se ha hecho, basada en el derecho natural, el utilitarismo o en principios racionalistas? Y así podrían formularse muchas más preguntas. Pero lo que no podemos ignorar es el problema clave que formuló Hayek desde su teoría de los órdenes extensos: no cualquier tipo de moral puede sostener un orden de cooperación humana tan 
complejo como el mercado, capaz de coordinar la información de millones de seres humanos. En otras palabras: no debemos aplicar, sin un discernimiento riguroso, una «forma» de moralidad (propia de comunidades pequeñas) que ha perdido su razón de ser en la «sociedad abierta».

\section{c) El discernimiento epistemológico en el plano económico}

Hace algunos años el Prof. E. M. Ureña S.J. escribió una obra titulada El Mito del Cristianismo Socialista donde desde su visión de economista y teólogo hacía una comparación, primero a nivel económico entre capitalismo y socialismo, y luego una reflexión ética de ambos sistemas, todo esto varios años antes de la caída del muro de Berlín. Concluía su obra diciéndonos: que no podíamos hacer saltos epistemológicos y hacer moral sobre el vacío científico; que primero debíamos informarnos de los problemas que implica la organización económica en un sistema y otro. Decir que el capitalismo es inmoral porque se basa en el lucro y el socialismo es éticamente admisible porqué busca la igualdad y no busca el beneficio, sin analizar lo que significa lucro en el interior del capitalismo o igualdad desde el socialismo planificado, son errores en los que la teología moral cae constantemente.

En esta misma línea mi trabajo, que quiere moverse en una línea de humanismo cristiano, ha intentado explicar desde otra perspectiva temas económicos sobre los que se ha hecho «moral» sin quizás haber entendido desde dentro de la economía de mercado su razón de ser. Por ello creo indispensable cambiar el paradigma desde donde estudiar el hecho económico: el método crítico del marxismo como el neo-clásico han sido los métodos históricos que he visto reflejados en nuestros manuales de teología moral $^{22}$ ¿no habrá llegado la hora de buscar otros aportes? Con lo anterior no estoy diciendo que la moral sea «ciencia segunda» de la economía, no, lo único que quiero afirmar es que la moral debe conocer en profundidad los problemas que la ciencia económica

22 Un buen ejemplo de lo que estoy diciendo puede verse en M. Vidal, Moral de Actitudes, t. III., Madrid 1988. También VV.AA., Praxis Cristiana, t. III, Madrid 1986. 
tiene por delante, y además saber que en su mismo interior hay modelos de análisis diversos de un mismo hecho, que pueden cuestionar mucho de nuestros juicios morales. El austriaco es sólo uno y en la medida en que aporta nuevos elementos de comprensión, lo propongo como válido.

\section{Buscando un punto de convergencia: la teoría de la eficiencia dinámica}

Uno de los teóricos más importantes de la Escuela Austriaca —además de católico practicante- el profesor Jesús Huerta de Soto, ha desarrollado uno de los planteamientos que mayor fecundidad podrían tener en el futuro de la ciencia económica y, en particular, en el desarrollo de la DSI, es La teoría de la eficiencia dinámica.

Como bien señala en su ensayo, la ciencia económica ha estado dominada por el paradigma neoclásico de origen paretiano, influenciado por la mecánica clásica, por tanto, estático, donde la capacidad creativa y coordinativa de la función empresarial son inexistentes. En este modelo los recursos, los fines y los medios, estarían dados. Por tanto, el empresario -elemento clave en el paradigma dinámico - no existe y la riqueza o bienes, al estar «ahí» serían sólo un problema de distribución o de evitar en todo lo posible el despilfarro. Nada se crearía ni se destruiría, a lo más se transformaría. Las consecuencias que esto ha tenido en política económica, a través de la redistribución de la renta por el llamado Estado del Bienestar, son de sobra conocidas.

La pregunta que un estudioso de la DSI se hace es, ¿no será éste el paradigma que ha estado detrás de las reflexiones que en torno a la economía el magisterio ha hecho? Y me inclino a decir que sí.

En prácticamente todas las encíclicas sociales se ha dado por supuesto que la riqueza «existe» (o que los medios están «dados»), y que, por tanto, se tiene que distribuir justamente. Intención, por lo demás, legítima, noble y coherente por parte del magisterio. Pero ¿cómo se crea la riqueza, quién lleva adelante los procesos de crecimiento; quién está buscando las posibilidades nuevas 
para que el sistema se siga expandiendo? Y la DSI ya casi no tiene respuesta. Ha desconocido por completo la labor de la función empresarial.

Por eso es necesario empezar a descubrir las claves hermenéuticas que nos da la teoría de la eficiencia dinámica, donde, «lo importante no es tanto evitar el despilfarro de unos medios que se consideran conocidos y dados..., como el descubrir y crear continuamente nuevos fines y medios, impulsando la coordinación y asumiendo que en todo proceso empresarial siempre surgirán nuevos desajustes...», y descubrir que en todo este proceso es el ser humano, con su capacidad libre y creadora el que lleva adelante el proceso de coordinación social mediante la perspicacia empresarial.

Por último quiero destacar uno de los aspectos desarrollados en este trabajo, y es la relación entre justicia y eficiencia dinámica: es justo lo que es eficiente en la promoción de la creatividad humana y es eficiente lo que justamente el sujeto puede adquirir gracias a su creatividad empresarial (desde el respeto a la vida, la propiedad privada y el cumplimiento de los contratos). Una de los aportes que más posibilidad de diálogo podría tener con la teología moral católica, es cuando el profesor dice: «de ahí la gran trascendencia que tienen determinadas instituciones sociales a la hora de transmitir e impulsar la observancia de estos principios de moral personal que, por su propia naturaleza, no pueden imponerse por la fuerza, pero que, a su vez, son de gran importancia para hacer posible la eficiencia dinámica de la sociedad. Así, por ejemplo a través de la religión y de la familia estos principios se internalizan por los diferentes seres humanos, que así aprenden a cumplirlos de forma habitual y a transmitirlos de generación en generación». Nuestro autor nos dice - y nos desafía a los teólogos católicos-que la religión no es un producto secundario más de la cultura, sino la posibilidad misma de que el «orden extenso» del mercado pueda seguir expandiéndose, tanto en bienes como en su principal capital, las personas. 


\section{Un nuevo camino a seguir: hacia una «teología económica» de la creatividad humana}

Ya sólo para terminar (mucho ya lo dije en el punto IV.3), la teología moral católica tiene en el humanismo austriaco el mejor de los aliados a la hora de concebir una moderna teología moral y de interpretar con nuevos elementos de análisis la complejidad del proceso económico y social, condicionado, como hemos visto, por las pautas morales que de manera evolutiva se han ido plasmando en las instituciones. Es decir, ¡la religión y la moral son parte también de este proceso! De hecho tienen una palabra de primera importancia en este orden de cooperación humana.

Si como hemos visto el ser humano, libre y creativo, es el protagonista de todo el proceso social, y de cara a la interpretación cristiana Dios le he dotado de inteligencia y voluntad, ¿por qué no diseñar una teología donde la inteligencia creadora del ser humano, y su función empresarial se vean más bien como la culminación de lo que el creador quiere de cada uno de nosotros? ¿Será esto quizás estirar demasiado la reflexión teológica? O mejor, ¿por qué no aventurarse a escribir una teología de la creatividad humana (para no llamarla de la «riqueza») como el don más grande que tenemos: buscar nuevos horizontes, no conformándonos con lo que nos rodea, queriendo ir, junto con otras personas libres, más allá de los condicionamientos del presente? Ahí queda el desafío. 